\title{
Enhanced Communication Skills and C-reactive Protein Point-of-Care Testing for Respiratory Tract Infection: 3.5-year Follow- up of a Cluster Randomized Trial
}

\author{
Jochen W. L. Cals, MD, PbD ${ }^{1}$ \\ Leon de Bock, MD \\ Pieter-Jan H. W. Beckers, MD ${ }^{1}$ \\ Nick A. Francis, $M D, P b D^{2}$ \\ Rogier M. Hopstaken, MD, $P b D^{3}$ \\ Kerenza Hood, PbD \\ Eefje G. P. M. de Bont, $M D^{1}$ \\ Christopher C. Butler, $M D^{2}$ \\ Geert-Jan Dinant, $M D, P b D^{1}$
}

'Department of General Practice, CAPHRI School for Public Health and Primary Care, Maastricht University Medical Centre, The Netherlands

${ }^{2}$ Institute of Primary Care and Public Health, School of Medicine, Cardiff University, Cardiff, United Kingdom

${ }^{3}$ Saltro Diagnostic Centre, Utrecht, The Netherlands

${ }^{4}$ South East Wales Trials Unit, School of Medicine, Cardiff University, United Kingdom

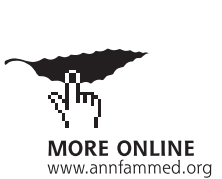

Conflicts of interest: Rogier Hopstaken bas received travel/lecture funds from Axis-Shield (Norway) and Orion Diagnostica (Finland), both manufacturers of point-of-care C-reactive protein devices. All other authors declare no conflict of interest.

\section{CORRESPONDING AUTHOR}

Jochen W. L. Cals, MD, PhD

Department of General Practice

Maastricht University

PO Box 616

6200 MD Maastricht

The Netherlands

j.cals@maastrichtuniversity.nl

\begin{abstract}
PURPOSE The purpose of the study was to assess the long-term effect of family physicians' use of C-reactive protein (CRP) point-of-care testing and/or physician training in enhanced communication skills on office visit rates and antibiotic prescriptions for patients with respiratory tract infections.
\end{abstract}

METHODS We conducted a 3.5-year follow-up of a pragmatic, factorial, clusterrandomized controlled trial; 379 patients (20 family practices in the Netherlands) who visited their family physician for acute cough were enrolled in the trial and had follow-up data available (88\% of original trial cohort). Main outcome measures were the average number of episodes of respiratory tract infections for which patients visited their family physician per patient per year (PPPY), and the percentage of the episodes for which patients were treated with antibiotics during follow-up.

RESULTS The mean number of episodes of respiratory tract infections during follow-up was 0.40 PPPY in the CRP test group and 0.56 PPPY in the no CRP test group $(P=.12)$. In the communication skills training group, there was a mean of 0.36 PPPY episodes of respiratory tract infections, and in the no training group the mean was 0.57 PPPY ( $P=.09$ ). During follow-up $30.7 \%$ of all episodes of respiratory tract infection were treated with antibiotics in the CRP test group compared with $35.7 \%$ in the no test group $(P=.36)$. Family physicians trained in communication skills treated $26.3 \%$ of all episodes of respiratory tract infection with antibiotics compared with $39.1 \%$ treated by family physicians without training in communication skills $(P=.02)$

CONCLUSIONS Family physicians' use of CRP point-of-care testing and/or training in enhanced communication skills did not significantly affect office visit rates related to respiratory tract infections. Patients who saw a family physician trained in enhanced communication skills were prescribed significantly fewer antibiotics during episodes of respiratory tract infection in the subsequent 3.5 years.

Ann Fam Med 2013;11:157-164. doi:10.1370/afm.1477.

\section{INTRODUCTION}

$\mathrm{R}$ espiratory tract infections are the most common reasons for acute care office visits and antibiotic prescribing in primary care. ${ }^{1,2}$ Reducing overprescribing of antibiotics for respiratory tract infections is essential in an era of increasing antimicrobial resistance. ${ }^{3}$ Important determinants influencing overprescription of antibiotics are patients' expectations of antibiotics, physicians' assumptions regarding these expectations, and physicians' diagnostic uncertainty in differentiating serious from selflimiting disease. ${ }^{4,5}$ Differentiating those patients who are more likely to benefit from antibiotics from those who are unlikely to benefit is consid- 
ered a priority for general medical practice in managing respiratory tract infections. ${ }^{6}$

C-reactive protein (CRP) is a widely used and acknowledged marker to diagnose and monitor infections in secondary care. Diagnostic studies have emerged supporting the role of CRP testing in primary care as an additional diagnostic tool for managing lower respiratory tract infection. ${ }^{7,8}$ Robustness of the CRP point-of-care tests is now firmly established, with studies showing reliability and accuracy of test results obtained from office-based devices when compared with laboratory standards. ${ }^{9,10}$ A systematic review of the diagnostic role of CRP testing in lower respiratory tract infections in primary care showed that CRP levels were a strong predictor in differentiating pneumonia from acute bronchitis. ${ }^{11}$

In 2 randomized trials including 688 primary care patients with respiratory tract infection, we were able to reduce antibiotic prescribing by family physicians exposed to communication skills training or through use of CRP point-of-care testing without adversely affecting patients' satisfaction or recovery. ${ }^{12-14}$ The major contribution of CRP point-of-care testing seems to be in decreasing physician uncertainty. To participating physicians we stressed that a CRP test result could add useful information in identifying those patients at low risk of a complicated illness course. We observed the greatest antibiotic prescribing reduction in patients with CRP levels of less than $20 \mathrm{mg} / \mathrm{L}$. A cutoff value of $20 \mathrm{mg} / \mathrm{L}$ can be used to withhold antibiotic treatment in most patients with a low value (less than $75 \%$ of patients with lower respiratory tract infection in primary care). Patients with a CRP value higher than $100 \mathrm{mg} / \mathrm{L}$ (approximately $5 \%$ of patients) should receive antibiotics, whereas patients with intermediately elevated values ranging between 21 and $99 \mathrm{mg} / \mathrm{L}$ (20\% of patients) should be carefully assessed based on the combination of medical history, physical examination, and CRP value, and a delayed prescription for antibiotics can be considered in selected cases.

The long-term effect of these interventions on medicalizing acute illness is unknown, however. For example, is has been suggested that point-of-care testing for common infections may promote help-seeking behavior for future similar symptoms. On the other hand, enhanced communication during the office visit may promote self-care, thus reducing future consulting in these patients. No study has so far measured the long-term effects of such interventions.

We therefore followed up a randomized trial cohort of 431 patients $^{12}$ to determine long-term effects on physician visits and antibiotic prescriptions for patients after management by family physicians trained in enhanced communication skills and who used CRP point-of-care testing.

\section{METHODS}

Our study is a long-term follow-up of a pragmatic, factorial, cluster-randomized controlled trial assessing an illness-focused and a disease-focused intervention in the management of acute cough caused by lower respiratory tract infection in primary care. The initial trial evaluated the effect of family physicians' use of point-of-care CRP testing and physician communication skills training, both separately and combined, on antibiotic prescribing for lower respiratory tract infection. ${ }^{12}$ In the original trial, 431 adult patients with lower respiratory tract infection were enrolled by 40 Dutch family physicians from 20 family practices in the Southeastern part of the Netherlands. Practices were randomly assigned into 4 groups: (1) physician use of CRP testing, (2) physician communication skills training, (3) both interventions combined, and (4) usual care. Details of the interventions and study methods, including the exact inclusion criteria and the trial results, can be accessed elsewhere. ${ }^{12,13,15,16}$ Patients were recruited in the winter periods from September 2005 until March 2007 and were observed until July 2010. Thus, the current study focuses on the effects of the interventions on patients' subsequent office visit rates to their family physician for episodes of respiratory tract infection and associated antibiotic prescriptions for a 3.5-year follow-up period.

\section{Data Collection}

Patients in the Netherlands are registered with a single family physician, ensuring continuity of primary care medical records. We recorded episodes of respiratory tract infection leading to office visits from the end of the original 28-day follow-up period until July 1, 2010, by reviewing the medical records of the enrolled patients, which resulted in a follow-up period for every patient (follow-up period). We also recorded episodes of respiratory tract infection leading to office visits for the exact same period preceding the office visit in which the patient was recruited into the trial (baseline period). Consequently, the baseline period was of the same duration as the follow-up period for every patient, resulting in these definitions: the baseline period comprised the preintervention years (years before the trial); the follow-up period comprised the postintervention years (years after the trial).

Deceased patients were excluded. Similarly, patients who moved practices were excluded if their medical records could not be retrieved. If patients had changed practices but their medical records were still completely 
accessible for a specific follow-up duration, we adjusted the recording periods both for baseline and follow-up.

Two researchers (P.H.W.B. and L.B.) visited all the original participating practices, and data were extracted from the patients' medical records systems for the recording periods previously described. The following variables were recorded for both baseline and follow-up periods: the number of respiratory tract infection episodes, the total number of respiratory tract infection-related office visits within each episode (including telephone calls), antibiotic prescribing per episode, use of additional diagnostic tests including CRP, and comorbidity. Episodes of respiratory tract infection were classified according to the International Classification of Primary Care codes (ICPC): cough (R05), acute laryngitis/tracheitis (R77), acute bronchitis/ bronchiolitis (R78), pneumonia (R81), exacerbation of chronic obstructive pulmonary disease (R95), whooping cough (R71), Q-fever, sneezing/nasal congestion (R07), sinus symptom/complaint (R09), acute/chronic sinusitis (R75), throat symptom/complaint (R21), tonsils symptom/complaint (R22), acute tonsillitis (R76), influenza (R80), and acute upper respiratory infection (R74). We collected information on the occurrence of complications (hospital admission) during both periods. Data were double entered. In case of discrepancies the original data were checked.

\section{Outcomes}

The primary outcome was the average number of episodes of respiratory tract infection during the follow-up period for which patients consulted their physician per patient per year (PPPY) and the proportion of these episodes that resulted in an antibiotic prescription.

\section{Data Analysis}

The 4 previously described groups were combined for analysis as follows: physician use of CRP testing $(1+3)$ compared with no CRP test $(2+4)$ (controlling for the effect of physician training in enhanced communication skills in the model); and physician training in enhanced communication skills $(2+3)$ compared with no training $(1+4)$ (controlling for the effects of CRP testing in the model).

Discrete variables were expressed as counts (percentages) and continuous variables as means (standard deviations), unless stated otherwise. Differences in baseline characteristics were assessed using the $\chi^{2}$ test or Mann-Whitney test. Differences between physician office visit rates at baseline and office visit rates during follow-up in intervention and control arms were tested using Wilcoxon matched pairs signed rank test.

Episodes of respiratory tract infection per patient per year and the proportion of episodes resulting in an antibiotic prescription during baseline and follow-up were calculated with corresponding point estimates and $95 \%$ confidence intervals, as was the proportion of episodes that resulted in an antibiotic prescription.

The primary analysis compares the effect of intervention and control groups on episodes of respiratory tract infection and antibiotic prescriptions during Follow-up. We used a multilevel linear regression model to account and correct for variation at the level of family physician and to adjust for the other intervention, baseline number of episodes per patient per year or baseline antibiotic prescribing (as applicable), and 1 predefined variable (chronic obstructive pulmonary disease [COPD] comorbidity). An interaction effect was tested and excluded from analysis if not significant. Exploratory analyses investigating the influence of patients' characteristics and interactions between the variables in the model were carried out as sensitivity analysis and included in the analysis if appropriate. Analysis was performed using SPSS 17.0 (SPSS Inc) and MLwiN 2.0 (Centre for Multilevel Modelling, University of Bristol).

The Ethics Committee of the Catharina Hospital in Eindhoven, the Netherlands (METC number M051529) approved the study.

\section{RESULTS}

\section{Follow-up and Patient Characteristics}

Of the original 431 patients enrolled in the trial, 379 patients $(87.9 \%)$ had accessible medical records for the follow-up period and were included in the current analyses (203 in the CRP test group vs 176 in the no CRP test group $;$ and 178 in the training in enhanced communication skills group vs 201 in the no training group). Fifty-two patients were excluded because their medical records were no longer available. Loss to follow-up rates ranged from $9.4 \%$ to $14.3 \%$ in the 4 groups. The flow chart (Figure 1) provides the reasons for exclusion. Recording periods were adjusted for another 54 patients because they moved from the practice. Data for analysis of the primary outcomes were available for all 379 patients.

Baseline characteristics of those patients included and those lost to follow-up for this study are shown in Table 1. Overall, the mean follow-up period was 3.67 years. Characteristics of patients in the intervention and control arms were comparable, except for antibiotic prescribing during the trial. Patients in the group of physicians using CRP testing and the group of physicians who had communication skills training were prescribed fewer antibiotics during the 28-day follow-up compared with patients in the control arms (Table 2), in line with the results of the original trial. ${ }^{12}$ 
Figure 1. Study flowchart.

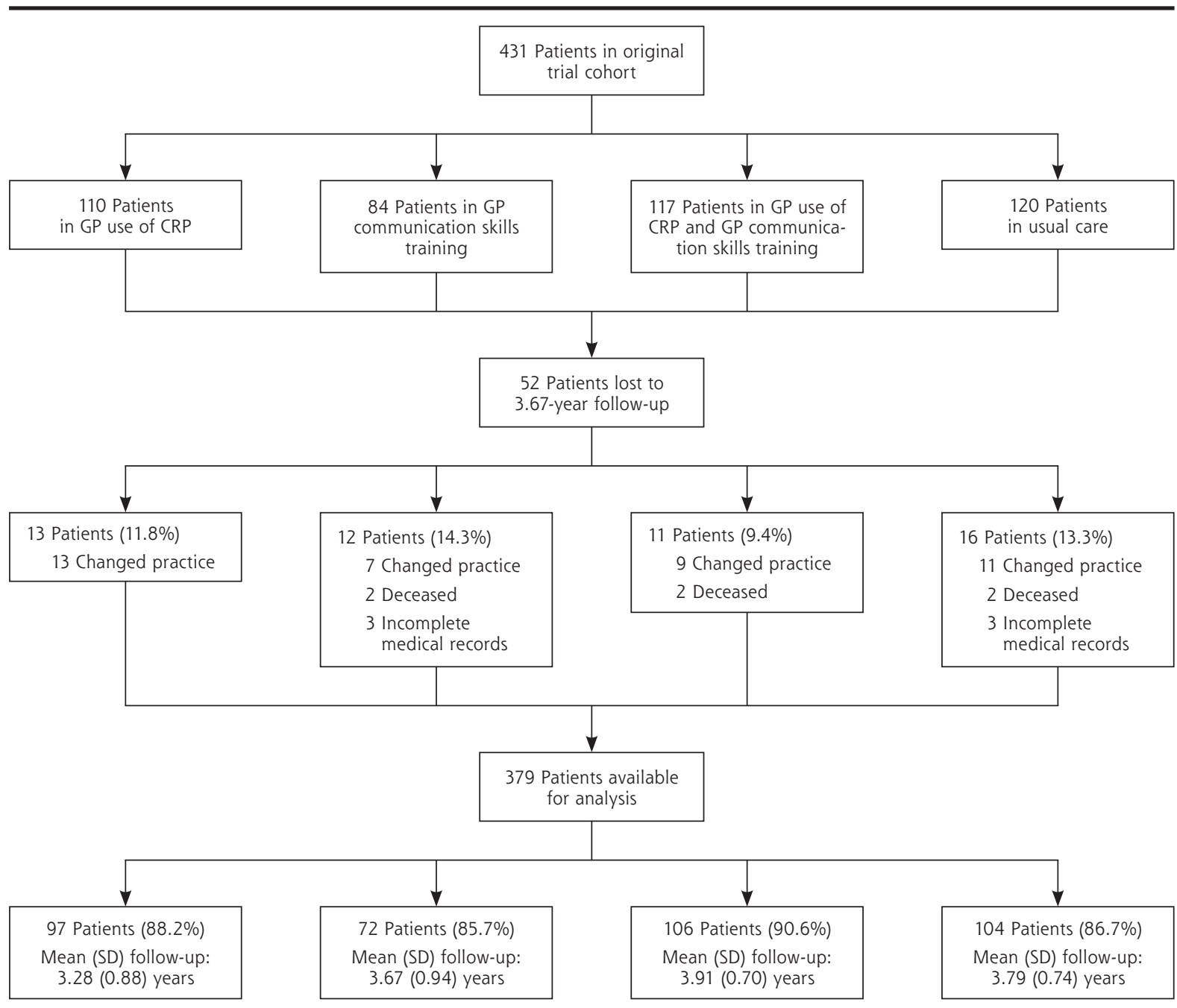

$\mathrm{CRP}=\mathrm{c}$-reactive protein; $\mathrm{GP}=$ general practitioner

At the index visit (the first visit in the original trial), 24 patients included for this follow-up study were given a diagnosis of COPD. During follow-up an additional 24 patients were given a diagnosis COPD, leading to a total of 48 patients with this condition.

\section{Office Visit Rates During Follow-up and Baseline Period}

Six hundred sixty-seven episodes of respiratory tract infection resulting in a total of 1,010 related office visits were registered in 379 patients (mean 1.51 office visits per episode) during follow-up. During the baseline period 586 episodes of respiratory tract infection led to a total of 881 related office visits (mean 1.50 office visits per episode).

Patients with COPD ( $\mathrm{n}=48,12.7 \%)$ were responsible for 135 (23.0\%) episodes and 188 (21.3\%) related office visits at baseline and 221 (33.3\%) episodes and $350(34.7 \%)$ related office visits during follow-up.

The mean numbers of episodes of respiratory tract infection per patient per year in the intervention and control arms are reported in Supplemental Table 1, available at http://annfammed.org/content/11/2/157/suppl/DC1. We found an increase in episodes of respiratory tract infection during the follow-up period compared with the baseline period in the no CRP test group. After exclusion of COPD patients, this effect was no longer statistically significant.

\section{Effect of Interventions on Office Visits for Episodes of Respiratory Tract Infection and Associated Antibiotic Prescriptions}

We found no significant differences between intervention and control arms for episodes of respiratory tract 
infection during follow-up (Table 3). The mean number of episodes during follow-up was 0.40 PPPY in the CRP test group, and 0.56 PPPY in the no CRP test group $(P=.12)$. The mean number of episodes in the com- munication skills training group and no training group were 0.36 PPPY and 0.57 PPPY, respectively $(P=.09)$.

Baseline antibiotic prescription rates per episode of respiratory tract infection were $40.7 \%$ (95\% CI,

\begin{tabular}{|c|c|c|c|c|}
\hline Characteristics & $\begin{array}{l}\text { Patients in } \\
\text { Original Trial } \\
N=431\end{array}$ & $\begin{array}{l}\text { Patients } \\
\text { Available for } \\
\text { Follow-up } \\
n=379\end{array}$ & $\begin{array}{l}\text { Patients } \\
\text { Lost to } \\
\text { Follow-up } \\
n=52\end{array}$ & $\begin{array}{c}P \\
\text { Value }\end{array}$ \\
\hline Women, No. (\%) & $265(61.5)$ & $235(62.0)$ & $30(57.7)$ & .55 \\
\hline Age, mean (SD), y & $49.9(15.3)$ & $49.9(15.0)$ & $49.8(17.6)$ & .93 \\
\hline \multicolumn{5}{|l|}{$\begin{array}{l}\text { Comorbidity at index visit, } \\
\text { No. (\%) }\end{array}$} \\
\hline COPD & $31(7.2)$ & $24(6.3)$ & $7(13.5)$ & .06 \\
\hline Asthma & $39(9)$ & $31(8.2)$ & $8(15.4)$ & .09 \\
\hline \multicolumn{5}{|l|}{ Antibiotics prescribed, No. (\%) } \\
\hline At index visit of trial & $178(41.3)$ & $160(42.2)$ & $18(34.6)$ & .30 \\
\hline $\begin{array}{l}\text { During 28-day follow-up } \\
\text { of trial }\end{array}$ & $221(51.3)$ & $197(52.0)$ & $24(46.2)$ & .43 \\
\hline
\end{tabular}

COPD = chronic obstructive pulmonary disease.

Note: data in this table represent information recorded during the index visit and 28-day follow-up of the original trial.

a $P$ values come from Mann-Whitney test (age) or $\varkappa^{2}$ test (other variables) comparing those available for followup with those lost to follow-up.
$34.5 \%-46.7 \%)$ vs $34.1 \%(95 \% \mathrm{CI}$, $27 \% .8-40.3 \%)$ in the CRP vs no CRP group and $34.5 \%(95 \% \mathrm{CI}$, $28.3 \%-40.7 \%$ ) vs $40.4 \%$ (95\% CI, $34.2 \%-46.6 \%)$ in the training vs no training group.

Table 4 shows the long-term effects of both interventions on antibiotic prescribing during follow-up in a multilevel linear regression model, adjusted for baseline prescribing, the other intervention, and COPD comorbidity. Patients managed by a physician who used a CRP pointof-care test received a prescription for antibiotics for $30.7 \%$ of all episodes of respiratory tract infection for which they consulted at least once, whereas patients managed by a physi-

Table 2. Characteristics of Patients With Complete Follow-up Data in Intervention and Control Arms

\begin{tabular}{|c|c|c|c|c|c|c|}
\hline Characteristics & $\begin{array}{l}\text { CRP Test } \\
(n=203)\end{array}$ & $\begin{array}{c}\text { No CRP Test } \\
(n=176)\end{array}$ & $\begin{array}{c}P \\
\text { Value }^{a}\end{array}$ & $\begin{array}{l}\text { Communication } \\
\text { Skills Training } \\
(n=178)\end{array}$ & $\begin{array}{l}\text { No Communication } \\
\text { Skills Training } \\
(n=201)\end{array}$ & $\begin{array}{c}P \\
\text { Value }^{a}\end{array}$ \\
\hline Women, No. (\%) & $119(58.6)$ & $116(65.9)$ & .15 & $118(66.3)$ & $117(58.2)$ & .11 \\
\hline Age, mean (SD), y & $49.4(14.5)$ & $50.4(15.6)$ & .53 & $51.0(15.3)$ & $48.8(14.6)$ & .12 \\
\hline \multicolumn{7}{|l|}{ Comorbidity, No. (\%) } \\
\hline COPD & $22(10.8)$ & $26(14.8)$ & .25 & $20(11.2)$ & $28(13.9)$ & .43 \\
\hline Asthma & $27(13.3)$ & $28(15.9)$ & .47 & $27(15.2)$ & $28(13.9)$ & .73 \\
\hline \multicolumn{7}{|l|}{ Antibiotics prescribed, No. (\%) } \\
\hline At index visit of trial & $64(31.5)$ & $96(54.5)$ & $<.01$ & $49(27.5)$ & $111(55.2)$ & $<.01$ \\
\hline During 28-day follow-up trial & $92(45.3)$ & $105(59.7)$ & $<.01$ & $69(38.8)$ & $128(63.7)$ & $<.01$ \\
\hline
\end{tabular}

\section{Table 3. Respiratory Tract Infections During Follow-up in Intervention and Control Arms}

\begin{tabular}{|c|c|c|c|c|c|}
\hline & \multicolumn{2}{|c|}{ RTI Episodes PPPY } & \multirow[b]{2}{*}{$\begin{array}{l}\text { Uncorrected } \\
\text { Difference }\end{array}$} & \multirow[b]{2}{*}{$\begin{array}{c}\text { Corrected } \\
\text { Difference }^{a}\end{array}$} & \multirow[b]{2}{*}{$P$ Value ${ }^{a}$} \\
\hline & $\begin{array}{c}\text { Control Group } \\
\text { Mean No. }(95 \% \mathrm{Cl})\end{array}$ & $\begin{array}{l}\text { Intervention Group } \\
\text { Mean No. }(95 \% \mathrm{Cl})\end{array}$ & & & \\
\hline C-reactive protein test & $0.56(0.43-0.68)$ & $0.40(0.33-0.47)$ & -0.16 & -0.10 & .12 \\
\hline Communication skills training & $0.57(0.46-0.69)$ & $0.36(0.30-0.42)$ & -0.21 & -0.11 & .09 \\
\hline \multicolumn{6}{|c|}{ COPD = chronic obstructive pulmonary disease; PPPY = per patient per year; $\mathrm{RTI}=$ respiratory tract infection. } \\
\hline \multicolumn{6}{|c|}{ Note: Intervention included point of care C-reactive protein testing or training in enhanced communication skills. } \\
\hline \multicolumn{6}{|c|}{$\begin{array}{l}\text { a } P \text { values from multilevel linear regression model to account and correct for variation at level of family physician, and to adjust for both interventions, the number } 0 \\
\text { RTI episodes PPPY during baseline period, COPD comorbidity. }\end{array}$} \\
\hline
\end{tabular}


Table 4. Percentage of Episodes of Respiratory Tract Infection Treated With Antibiotics During Follow-up in Intervention and Control Arms

\begin{tabular}{|c|c|c|c|c|c|}
\hline & \multicolumn{2}{|c|}{ RTI Episodes Treated With Antibiotics } & \multirow[b]{2}{*}{$\begin{array}{l}\text { Uncorrected } \\
\text { Difference }\end{array}$} & \multirow[b]{2}{*}{$\begin{array}{l}\text { Corrected } \\
\text { Difference }^{a}\end{array}$} & \multirow[b]{2}{*}{$P$ Value $^{a}$} \\
\hline & $\begin{array}{l}\text { Control Group } \\
\%(95 \% \mathrm{Cl})\end{array}$ & $\begin{array}{l}\text { Intervention Group } \\
\%(95 \% \mathrm{Cl})\end{array}$ & & & \\
\hline C-reactive protein test & $35.7(29.5-42.0)$ & $30.7(25.0-36.4)$ & -5.0 & -4.1 & .36 \\
\hline Communication skills training & $39.1(33.1-45.1)$ & $26.3(20.6-32.0)$ & -12.8 & -10.4 & .02 \\
\hline
\end{tabular}

cian who did not use the test received a prescription for antibiotics for $35.7 \%$ of episodes $(P=.36)$. Patients managed by a physician who had training in enhanced communication skills received an antibiotic prescription in $26.3 \%$ of all episodes during the 3.5 year follow-up, whereas patients managed by physician who did not have training in communication skills received a antibiotic prescription for $39.1 \%$ of all episodes $(P=.02)$. The interaction term between the 2 interventions was not significant for illness episodes $(P=.17)$ or antibiotic prescribing during follow-up $(P=.57)$.

\section{Use of Tests and Serious Adverse Events}

During all follow-up years a CRP point-of-care test was only performed 11 times for 294 episodes of respiratory tract infection in the 203 patients in the CRP test group (3.7\% of episodes). Of the 667 episodes of respiratory tract infection during follow-up of the 379 total study patients, 8 episodes ( 5 patients) led to hospital admission: 5 episodes ( 2 patients; 4 exacerbations of COPD and 1 case of pneumonia) in the usual care group 1 episode (exacerbation of COPD) in the physician group that used CRP testing; and 2 episodes (pneumonia) in the combined intervention group.

\section{DISCUSSION}

\section{Summary and Main Findings}

A single office visit with a family physician who used a CRP point-of-care test and/or who had received training in enhanced communication skills had no effect on the rate of office visits for respiratory tract infection episodes during the subsequent 3.5 years. COPD patients showed an increase in frequency of office visits across all groups. Patients managed by a physician trained in enhanced communication skills were less likely to be prescribed antibiotics for episodes of respiratory tract infection for which they consulted during the 3.5-year follow-up. This long-term effect was not observed for CRP testing.

Concerns have been expressed about the potential medicalization of point-of-care testing in family practice. ${ }^{17,18}$ We found, however, no evidence to suggest that the disease-focused intervention effect of a point-of-care test to rule out serious infection resulted in a subsequent increase in office visit rates. Additionally, giving patients evidence-based information by physicians trained in illness-focused communication skills could theoretically lead to fewer visits through increased patient self-management of future respiratory tract infections. We did observe a trend toward fewer visits for similar illness episodes; however, we did not observe a significant effect in this long-term follow-up study.

\section{Strengths and Weaknesses of the Study}

Using medical records to perform this follow-up study has limitations. To correct for differences in follow-up duration, we calculated the number of respiratory tract infection episodes per patient per year. By using this outcome measure, we can be confident that all patients weighted equally in the analysis. We specifically chose an end date in July so the number of winter days in both periods would be similar. Seasonal and yearly differences in causative microorganisms could be a factor however, one would expect effects on visits to be comparable across the groups.

We recognize the large interpractitioner variation in disease labeling for respiratory tract infection. ${ }^{19}$ As a result, clear distinctions between visits for upper and lower respiratory tract infections were not presented. Additionally, in contrast to the original trial, we collected no physician or patient-recorded data on disease severity. We can therefore not judge whether visits related to respiratory tract infection were for self-limiting or more serious disease. Nonetheless, patients with respiratory tract infection, especially lower respiratory tract infection with a bothersome cough, often seek symptom relief and reassurance. ${ }^{20}$ Given this limitation, we must be cautious in estimating the effect of the interventions on antibiotic prescribing during longterm follow-up. Nevertheless, it seems unlikely that the detected effect of communication skills training on antibiotic prescribing is a result of differences in the 
range and severity of illness episodes, with visit rates in general being unaltered in all groups.

With COPD, patients' exacerbations are more likely to occur with time as the severity of disease increases. ${ }^{21}$ In our study, COPD patients (12.7\%) were responsible for approximately one-third of all visits related to respiratory tract infection during follow-up. It is quite unlikely that the observed increase in office visit rate over time in this group was a result of either of the interventions. The increase in office visits was most prominent in the usual care group. To exclude the influence of this chronic progressive disease, we performed analyses for the primary outcomes correcting for the diagnosis of COPD.

\section{Disease and Illness-Focused Approaches in Primary Care}

By taking an illness-focused approach, accurate communication between patient and physician can improve the appropriateness of prescribing antibiotics, particularly when the family physician is certain of the diagnosis. ${ }^{4}$ When the physician is dealing with diagnostic uncertainty, using point-of-care biomarkers may be helpful in targeting inappropriate antibiotic prescribing, as clinical judgment alone lacks specificity in differentiating serious from mild infection. ${ }^{22}$ Because an illness-focused intervention will appeal to the patient's interest, one would expect that solid evidence-based information from the physician could lower future office visit rates. Although we did not find a significant effect, we observed a trend toward fewer visits after seeing a family physician trained in the use of advanced communication skills. The current analysis may have been underpowered to detect a significant effect, however.

We have no information about how often communication skills were used during follow-up. We previously reported sustained competence in implementing these skills for a period of 6 months, ${ }_{1}^{16}$ and sustainable uptake of the skills during the 2-year trial was high. ${ }^{12}$ Although one could expect that evidence-based information on the natural course and treatment of respiratory tract infection could lead to decreased visits for similar episodes in the future, our current data do not support this outcome. Yet, the wider applicability of communication skills beyond lower respiratory tract infection may explain reduced antibiotic prescribing for respiratory tract infections by family physicians in general. ${ }^{23}$ Communication skills training using an interactive booklet led to reductions in antibiotic prescribing for children, and a recent multifaceted educational program that included online enhanced communication skills training led to reductions in all-cause oral antibiotic dispensing during a 1 -year follow-up period. ${ }^{24,25}$
In contrast, a disease-focused intervention, such as CRP testing, could increase the long-term likelihood of patients consulting for similar illnesses in the future (the so-called medicalization of self-limiting illness). In Scandinavia, CRP testing at the point of care has been widely introduced in primary care. The result has been excessive use of CRP testing in these countries with subsequent little value in accurately managing respiratory tract infections. ${ }^{26}$ This outcome is in sharp contrast with our findings, where the number of CRP measurements during the entire follow-up period was very low-only 11 measurements in 203 patients. For patients in our study, CRP testing did not specifically lead to increased demand to be retested for similar future symptoms, nor did the physicians who were exposed to the CRP test start using it regularly with the same patient for different illness episodes. These findings are consistent with previous qualitative findings of general physicians' attitudes, as well as national guidelines that recommend use of the test only in cases of diagnostic uncertainty. ${ }^{27,28}$ In our study, antibiotic prescribing rates during follow-up did not differ between physicians regardless of whether they were exposed to the test. It is possible that CRP pointof-care testing is advocated for selected cases of lower respiratory tract infection only and not for respiratory tract infection in general. Outpatient antibiotic prescribing figures for the Netherlands are among the lowest in Europe. ${ }^{29}$ Considering the effects on the interventions in the Dutch setting with already low antibiotic prescribing rates, even larger effects could be expected in other settings, as research shows that antibiotic prescribing for acute cough varies widely across Europe. ${ }^{30}$

Based on the effects of the interventions on shortterm antibiotic prescribing shown in the original trial, and the lack of effect on long-term family physician office visits, as shown in this follow-up study, implementation of both interventions on a larger scale can be advocated. Training physicians in the use of enhanced communication skills may have a wider long-term effect on the treatment of respiratory tract infections beyond acute cough to include reduced antibiotic prescribing.

To read or post commentaries in response to this article, see it online at http://www.annfammed.org/content/11/2/157.

Key words: respiratory tract infection; C-reactive protein; antibiotics; communication; family practice

Submitted March 23, 2012; submitted, revised, July 24, 2012; accepted August 8, 2012.

Author contributions: All authors contributed to the design and implementation of the study. Jochen Cals was responsible for running the project. Pieter-Jan Beckers and Leon de Bock collected the followup data in the practices and data analysis. Eefje de Bont assisted with antibiotic prescribing data. All authors interpreted the data and findings and all authors commented on the first draft and all further revisions. 
Jochen Cals is guarantor for the paper. The corresponding author (J.W.L.C.) had full access to all the data in the study and takes responsibility for the integrity of the data and the accuracy of the data analysis.

Funding support: The Netherlands Organisation for Health Research and Development (ZonMW grant 945-04010) funded the trial. The South East Wales Trial Unit, which $\mathrm{KH}$ directs, receives funding from the National Institute for Health and Social Care (NISCHR).

Disclaimer: The funders had no role in the design and conduct of the study; collection, management, analysis, and interpretation of the data; and preparation, review, or approval of the manuscript.

Previous presentation: Findings from this study were presented at the GRIN (General Practice Respiratory Infection Network) conference, October 2011, Barcelona, Spain.

Trial registration: Current Controlled Trials ISRCTN85154857.

Acknowledgments: We thank the participating family physicians and patients.

\section{References}

1. Macfarlane J, Holmes W, Gard P, et al. Prospective study of the incidence, aetiology and outcome of adult lower respiratory tract illness in the community. Thorax. 2001;56(2):109-114.

2. Kuyvenhoven MM, van Balen FA, Verheij TJ. Outpatient antibiotic prescriptions from 1992 to 2001 in the Netherlands. J Antimicrob Chemother. 2003;52(4):675-678

3. Nordberg P, Monnet DL, Cars O. Antibacterial Drug Resistance: Options for Concerted Action. Geneva : World Health Organization Department of Medicines Policy and Standards; 2005.

4. Butler CC, Kinnersley P, Prout H, Rollnick S, Edwards A, Elwyn G. Antibiotics and shared decision-making in primary care. J Antimicrob Chemother. 2001;48(3):435-440.

5. Little P, Dorward M, Warner G, Stephens K, Senior J, Moore M. Importance of patient pressure and perceived pressure and perceived medical need for investigations, referral, and prescribing in primary care: nested observational study. BMJ. 2004;328(7437):444.

6. Dinant GJ, Buntinx FF, Butler CC. The necessary shift from diagnostic to prognostic research. BMC Fam Pract. 2007;8:53.

7. Flanders SA, Stein J, Shochat G, et al. Performance of a bedside C-reactive protein test in the diagnosis of community-acquired pneumonia in adults with acute cough. Am J Med. 2004;116(8):529-535.

8. Hopstaken RM, Muris JWM, Knottnerus JA, Kester ADM, Rinkens PELM, Dinant GJ. Contributions of symptoms, signs, erythrocyte sedimentation rate, and C-reactive protein to a diagnosis of pneumonia in acute lower respiratory tract infection. Br J Gen Pract. 2003;53(490):358-364.

9. Esposito S, Tremolati E, Begliatti E, Bosis S, Gualtieri L, Principi N. Evaluation of a rapid bedside test for the quantitative determination of C-reactive protein. Clin Chem Lab Med. 2005;43(4):438-440.

10. Seamark DA, Backhouse SN, Powell R. Field-testing and validation in a primary care setting of a point-of-care test for C-reactive protein. Ann Clin Biochem. 2003;40(Pt 2):178-180.

11. van der Meer V, Neven AK, van den Broek PJ, Assendelft WJ. Diagnostic value of $C$ reactive protein in infections of the lower respiratory tract: systematic review. BMJ. 2005;331(7507):26-29.

12. Cals JW, Butler CC, Hopstaken RM, Hood K, Dinant GJ. Effect of point of care testing for $C$ reactive protein and training in communication skills on antibiotic use in lower respiratory tract infections: cluster randomised trial. BMJ. 2009;338:b1374.
13. Cals JW, Ament AJ, Hood K, et al. C-reactive protein point of care testing and physician communication skills training for lower respiratory tract infections in general practice: economic evaluation of a cluster randomized trial. J Eval Clin Pract. 2011;17(6):1059-1069.

14. Cals JW, Schot MJ, de Jong SA, Dinant GJ, Hopstaken RM. Point-ofcare C-reactive protein testing and antibiotic prescribing for respiratory tract infections: a randomized controlled trial. Ann Fam Med. 2010;8(2):124-133.

15. Cals JW, Hopstaken RM, Butler CC, Hood K, Severens JL, Dinant GJ. Improving management of patients with acute cough by C-reactive protein point of care testing and communication training (IMPAC3T): study protocol of a cluster randomised controlled trial. BMC Fam Pract. 2007;8:15.

16. Cals JW, Scheppers NA, Hopstaken RM, et al. Evidence based management of acute bronchitis; sustained competence of enhanced communication skills acquisition in general practice. Patient Educ Couns. 2007;68(3):270-278.

17. Hay $A D$, Jüttner KV. Antibiotics for acute cough in primary care. BMJ. 2009;338:b834.

18. Cals JW, Hood K, Aaftink N, et al. Predictors of patient-initiated reconsultation for lower respiratory tract infections in general practice. Br J Gen Pract. 2009;59(567):761-764.

19. Stocks N, Fahey T. Labelling of acute respiratory illness: evidence of between-practitioner variation in the UK. Fam Pract. 2002;19(4): 375-377.

20. van Driel $M L$, De Sutter $A$, Deveugele $M$, et al. Are sore throat patients who hope for antibiotics actually asking for pain relief? Ann Fam Med. 2006;4(6):494-499.

21. Hurst JR, Perera WR, Wilkinson TMA, Donaldson GC, Wedzicha JA Systemic and upper and lower airway inflammation at exacerbation of chronic obstructive pulmonary disease. Am J Respir Crit Care Med. 2006;173(1):71-78.

22. Hopstaken RM, Stobberingh EE, Knottnerus JA, et al. Clinical items not helpful in differentiating viral from bacterial lower respiratory tract infections in general practice. J Clin Epidemiol. 2005;58(2): 175-183.

23. Cals JW, Butler CC, Dinant GJ. 'Experience talks': physician prioritisation of contrasting interventions to optimise management of acute cough in general practice. Implement Sci. 2009;4:57

24. Francis NA, Butler CC, Hood K, Simpson S, Wood F, Nuttall J. Effect of using an interactive booklet about childhood respiratory tract infections in primary care consultations on reconsulting and antibiotic prescribing: a cluster randomised controlled trial. BMJ. 2009;339:b2885

25. Butler CC, Simpson SA, Dunstan F, et al. Effectiveness of multifaceted educational programme to reduce antibiotic dispensing in primary care: practice based randomised controlled trial. BMJ. 2012;344:d8173.

26. Engström S, Mölstad S, Lindström K, Nilsson G, Borgquist L. Excessive use of rapid tests in respiratory tract infections in Swedish primary health care. Scand J Infect Dis. 2004;36(3):213-218.

27. Cals JW, Chappin FH, Hopstaken RM, et al. C-reactive protein pointof-care testing for lower respiratory tract infections: a qualitative evaluation of experiences by GPs. Fam Pract. 2010;27(2):212-218.

28. Verheij T, Hopstaken R, Prins J, et al. NHG-Standaard Acuut hoesten. [Dutch College of General Practitioners Guidelines on Acute Cough]. Huisarts Wet. 2011;54(2):68-92.

29. Goossens H, Ferech M, Vander Stichele R, Elseviers M; ESAC Project Group. Outpatient antibiotic use in Europe and association with resistance: a cross-national database study. Lancet. 2005;365 (9459):579-587.

30. Butler CC, Hood K, Verheij T, et al. Variation in antibiotic prescribing and its impact on recovery in patients with acute cough in primary care: prospective study in 13 countries. BMJ. 2009;338:b2242. 